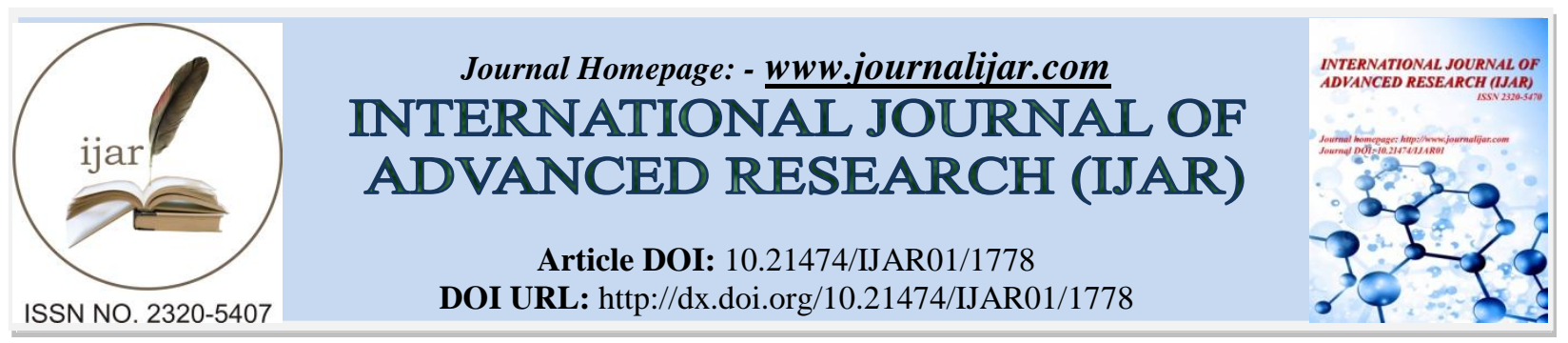

RESEARCH ARTICLE

\title{
ELECTROPLATING OF ZINC ON MILD STEEL OBTAINED BY RECOVERY OF EXHAUSTED BATTERIES LEACH SOLUTIONS FOR CORROSION PROTECTION.
}

\section{Mylarappa ${ }^{1,2}$, V. Venkata Lakshmi ${ }^{* 1}$, K. R. Vishnu Mahesh ${ }^{* * 3,4}$, H. P. Nagaswarupa ${ }^{5}$,} K. N Shravana Kumara ${ }^{5,7}$, D. M. K.Siddeswara ${ }^{6,7}$, N. Raghavendra ${ }^{8}$.

1. Research Centre, Department of Chemistry, AMC Engineering College, Bengaluru-560083, India. (Affiliated to Tumkur University)

2. Department of Studies and Research in Chemistry, Tumkur University, Tumkur, India.

3. Department of Chemistry, Dayananda Sagar College of Engineering, Bengaluru-560078, India.

4. Dr. Premachandra Sagar Center for Advance Functional Materials, Dayananda Sagar College of Engineering, Bengaluru-560078, India.

5. Research Centre, Department of Chemistry, EWIT, Bengaluru-560091, India.

6. Department of Chemistry, Jyothi Institute of technology, Bengaluru-560062, India.

7. Research and Development Centre, Bharathiar University, Coimbatore-641046, India.

8. CMRTU, RV College of Engineering, Bengaluru-560059, India.

\section{Manuscript Info}

Manuscript History

Received: 12 August 2016

Final Accepted: 12 September 2016

Published: October 2016

Key words:-

Hull cell, Mild steel, leach solution, corrosion studies.

\section{Abstract}

The main objective of the research work was mainly focused on Electroplating of Zinc on mild steel obtained by exhausted batteries leach solution using hull cell experiment for corrosion protection, which gives excellent corrosion resistance when used as coating material on mild steel. The mild steel was deposited into solution of zinc bath for varying voltage between $0.5 \mathrm{~V}$ and $2.0 \mathrm{~V}$. It was found that the sample plated at $1.5 \mathrm{~V}$ for 10 minutes gives the best plating surface finish. The Elemental composition and surface morphology of the coatings were analyzed by energy dispersive X-ray spectrometry (EDS), scanning electron microscopy (SEM). Surface area and line roughness of $\mathrm{Zn}$ coated samples were studied by Atomic force microscopy (AFM), micro hardness (HVN) and Open circuit potential (OCP), Taffel, and electrochemical impedance spectroscopy (EIS) were characterized by using Electro chemical work station for corrosion studies. The corrosion resistance was analyzed using $3.65 \%$ $\mathrm{NaCl}$ solution.

Copy Right, IJAR, 2016,. All rights reserved.

\section{Introduction:-}

Alkaline batteries make use of zinc powder as anode, a mixture of manganese dioxide and carbon as cathode and potassium hydroxide as the electrolyte. However, small amounts of $\mathrm{Hg}, \mathrm{Pb}$ and other heavy metals which are added to improve the performance of these devices. Therefore, these batteries can become a source of hazardous environmental pollutants when disposed of in an insufficient way. In addition, the natural resources for the production of batteries are restricted. So, the recovery of exhausted batteries will be increasingly important to both human health and the environment [1-2].

Corresponding Author:- V. Venkata Lakshmi, Research Centre, Department of Chemistry, AMC Engineering College, Bengaluru-560083, India.

K R Vishnu Mahesh, Dept. of Chemistry, Dayananda Sagar College of Engineering, Bengaluru-560078 
In recent years, several processes have been developed for the recycling of batteries in order to minimize the adverse environment impacts caused by their residues and to satisfy new regulations appearing around the world. The growing quantity of spent $\mathrm{Zn}-\mathrm{MnO}_{2}$ battery disposals is becoming a serious environmental problem. From an environmental point of view, recycling is the best choice to handle these residues. Electrodeposition of zinc has been widely used to produce protective anticorrosive coatings on iron and its alloys, reducing atmospheric corrosion on these metals [3-4].

Protective effect is due to the formation of a passivation layer over the zinc surface and on the other hand, to the galvanic sacrificial effect that zinc shows towards iron and its alloys. Electrodeposition of Zinc on mild steel plate is employed to provide corrosion protection, which gives tremendous corrosion resistance when used as coating material on mild steel. The mild steel is one of the world's most useful materials. Electroplated zinc coatings are considered as one of the main methods used for the corrosion protection of steel. Surface modification can significantly improve the stability of a metal system against corrosion [5].

Hull cell experiment was employed to optimize the current density, bath constituents, pH, Throwing power and current efficiency of the bath solution were determined at various current densities. The Hull cell provides four basic facilities for the electroplater in plating process control; optimization for current density range, optimization of additive concentration, recognition of effect of impurity effects and indication of macro-throwing power capability. Generally Hull cells used for the purpose of current distribution and deposit appearance. The following Steps are involved in the zinc deposition process. Caustic cleaning, Rinsing, Pickling, Rinsing, Flux solution, Drying Zinc bath and cooling $\&$ inspection [6-9].

The common type of Hull cell is the $267 \mathrm{ml}$ trapezoidal container utilizing a 4 in $(10.2 \mathrm{~cm})$ cathode panel inclined at $38^{\circ}$ to the parallel sides and having a 2 in $(5.1 \mathrm{~cm})$ anode which may be corrugated to increase its electrode area. A solution depth of 2 in $(5.1 \mathrm{~cm})$ gives a volume of $267 \mathrm{ml}$, a 3 in $(7.6 \mathrm{~cm})$ depth would give a volume of $320 \mathrm{ml}$. The cell can be made of a number of materials, including Perspex, Lucite, Polypropylene or glazed porcelain, depending upon temperature of usage and the corrositivity of the electrolyte. The aim of this study was to recover zinc present in exhausted zinc-carbon batteries through acidic leaching of the solid material. The leaching solution is then used as an electrolytic bath for the electrodeposition of the galvanic coating on mild steel.

\section{Experimental Procedure:- \\ Material and Methods;-}

In this experiment to keep the optimum electrolytic bath concentration of alkaline non-cyanide Zinc Bath solution,

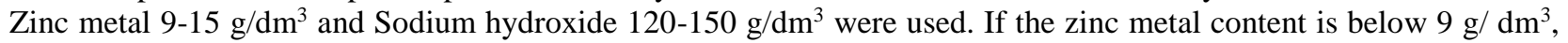
increase anode area and is above $15 \mathrm{~g} / \mathrm{dm}^{3}$, remove anode area from the bath after completion of the work. If $\mathrm{NaOH}$ is less make up to $140 \mathrm{~g} /$ liter. Hull cell studies were carried out using a $267 \mathrm{ml}$ cell at current $\mathrm{I}=0.5$ to $2 \mathrm{~A}$ and duration $\mathrm{t}=5$ to $10 \mathrm{~min}$. Suitably prepared mild steel cathode panel and zinc anode $(99.99 \%)$ were used.

The chemicals used were of AR grade and easily soluble in water. For preparation of solutions, distilled water was used. Surface preparation was done on the polishing machine with different grades of emery paper. The pickling of the sample was done in diluted $\mathrm{H}_{2} \mathrm{SO}_{4}$ solution, this was to remove all organic contaminates and oxides. The substrate was electrolytic degreased with alkaline solution by passing current in to the solution for 5 min and subsequent cleaning in water to remove all grease or oily contaminates. Electrically degreased metal substrate was immersed in a solution of dissolved Zinc salts and made the cathode by connecting it to the negative terminal of the rectifier of the electroplating bath. The anode was also immersed and connected to the positive terminal of the rectifier.

The anode was made up of pure Zinc rod about $99.99 \%$. The following parameters were varied, the voltage between $0.5 \mathrm{~V}$ and $2.0 \mathrm{~V}$. The substrate were plated at time variation of 5 to 10 minutes. More, so the immersion depth was kept constant and also check ampere during plating to make certain that it remains constant. After plating, remove panel from bath and rinse in running warm water (The rinsing was done in distilled water for 5 seconds) then latter air dried. Then the plates were subjected to bright dip in $1 \% \mathrm{HNO}_{3}$ for 2 to 5 seconds followed by water wash. 


\section{Result and Discussion:-}

SEM/EDS analysis of $\mathrm{Zn}$ deposited mild steel:-

The SEM/EDS images of the Zn coatings deposited from Sample A2 (Fig.1 a)) plated at applied voltage (1.5 V) shows morphological growth, surface finish and formation of a more densely packed corrosion product layer on coating surface, which enhanced the corrosion resistance. Thus the nature of the deposit is found to be uniform and adherent. No porosities was visible in the coating as seen from Fig.1a), which is attributed to the effect of the applied voltage on coating structure that tends to influence the perfect grain size and porosity free deposit obtained. In Fig 1b) indicated that there is perfect grain size with small porosities observed on the surface of mild steel.

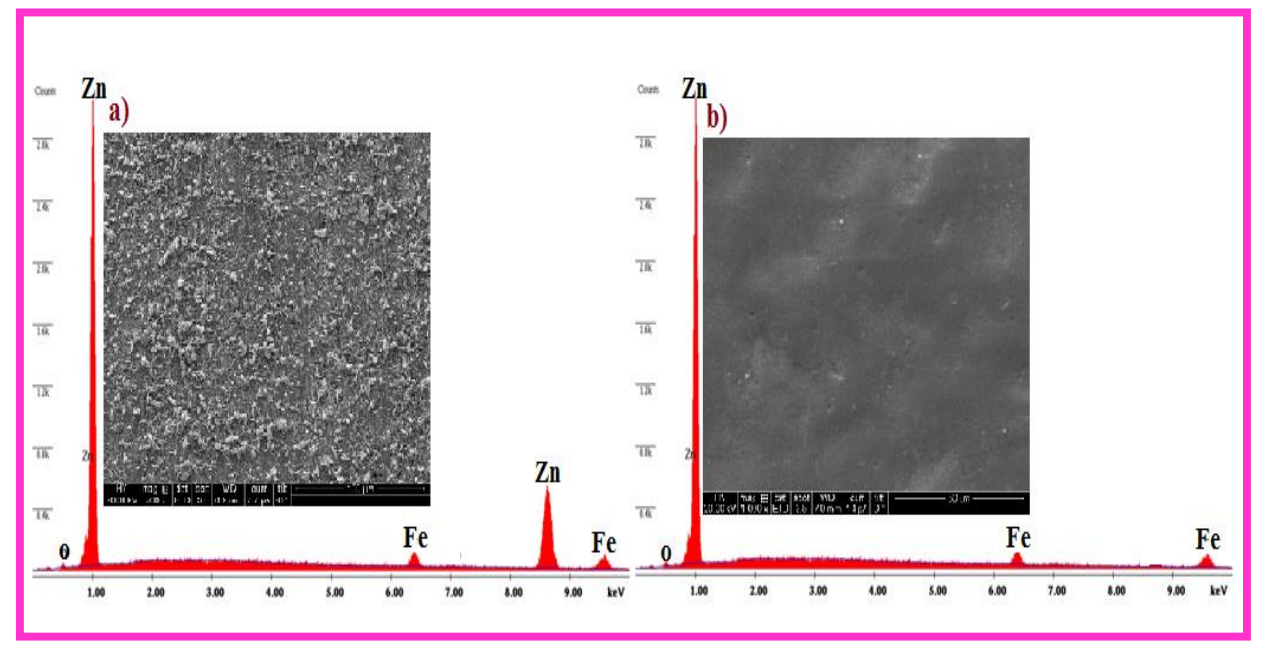

Fig 1:- SEM/EDS of Zinc deposited mild steel a) After plating b) Before plating.

\section{Atomic force Microscopy of $\mathrm{Zn}$ deposition:-}

Surface morphology and Zn particle size distribution in Mild steel were studied using AFM. Mild steel specimens were characterized using easy scan contact mode (static force) AFM supplied by M/s Sinsil International, Switzerland, the specifications of which are: Maximum Scan range: $70 \mu \mathrm{m}$, Maximum Z-range: $14 \mu \mathrm{m}$, Drive resolution Z: $0.21 \mathrm{~nm}$, Drive resolution XY: $1.1 \mathrm{~nm}$. Atomic force microscope was used to analyze the nature of crystal growth, adhesion properties, surface roughness of the plated samples made at different applied voltages and also non conducting samples can be measured. It was observed that the mild steel before electroplating(Fig.2) shows a surface area $8.944 \mathrm{mv}$ and surface roughness $8.477 \mathrm{mv}$ while the mild steel after electroplating(Fig.3) surface area $78.15 \mathrm{mv}$ and surface roughness $78.44 \mathrm{mv}$. The distribution of $\mathrm{Zn}$ particles with coarse size surface roughness increases significantly with the film thickness. It clearly indicated, surface roughness and adhesion increases as a result of applied voltages on the deposited mild steel surface because film thickness are influenced by particle size, distribution distance between anode and cathode and depth of immersion.
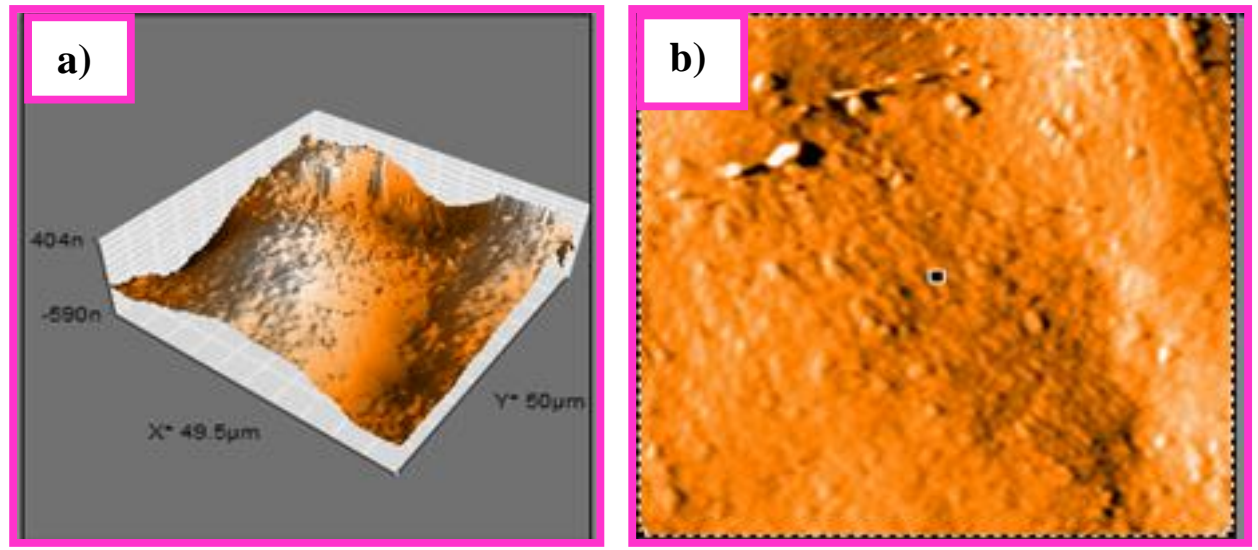

Fig 2:- AFM Images of the Mild steel before Zn plating a) 3-D Image b) roughness analysis 

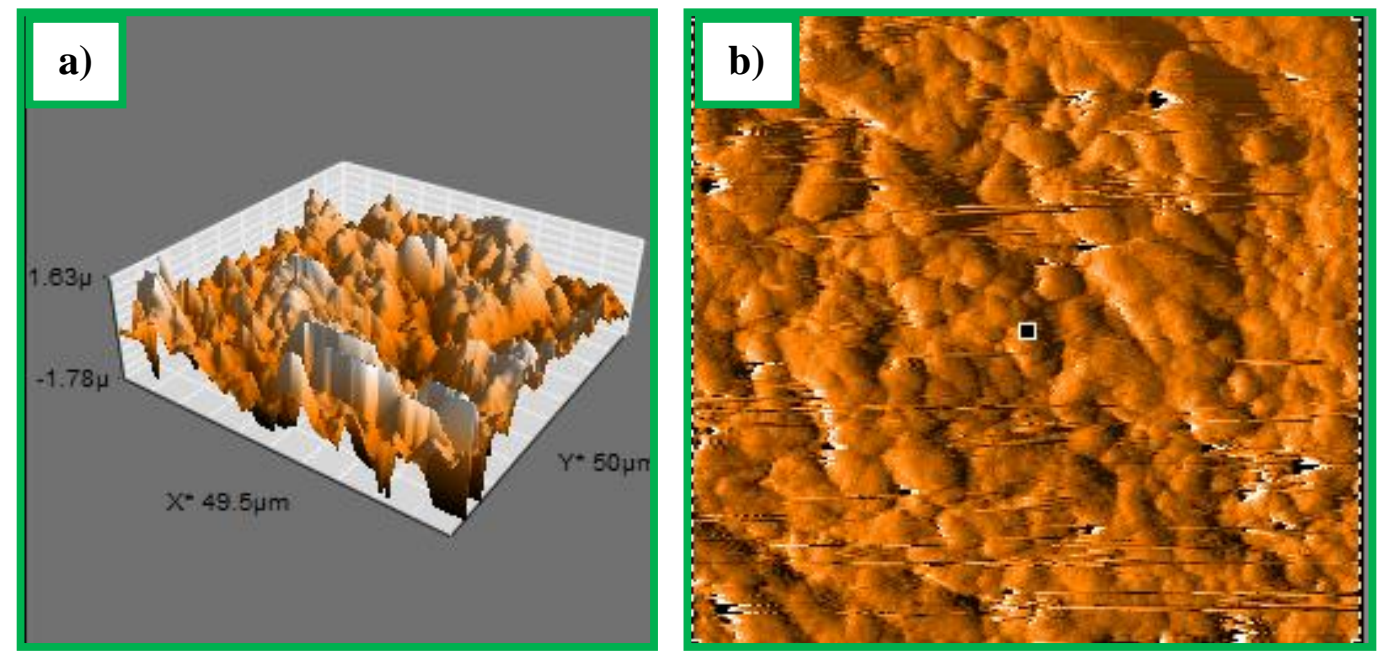

Fig 3:- AFM Images of the Mild steel after Zn plating

a) 3-D Image b) roughness analysis

\section{Micro Hardness Studies:-}

Micro hardness of Mild steel specimen was obtained by using Vickers's micro hardness tester supplied by MVH-1 Meta Tech Equipment's Pvt. Ltd. Pune, India. The micro hardness (HVN) value of the deposited coatings for sample at different applied potential was measured. From all indication hardness increases from $19.6 \mathrm{HVN}$ for base mild steel (Fig.4) to $20 \mathrm{HVN}$ for the deposited $\mathrm{Zn}$.the average value of after coating has the highest value of hardness. This is due to the influence of plating voltage that was double the micro hardness of substrate and higher hardness of the coating developed can be attributed to the fine grained structure of the deposit and dispersed particles in the fine grained structure.

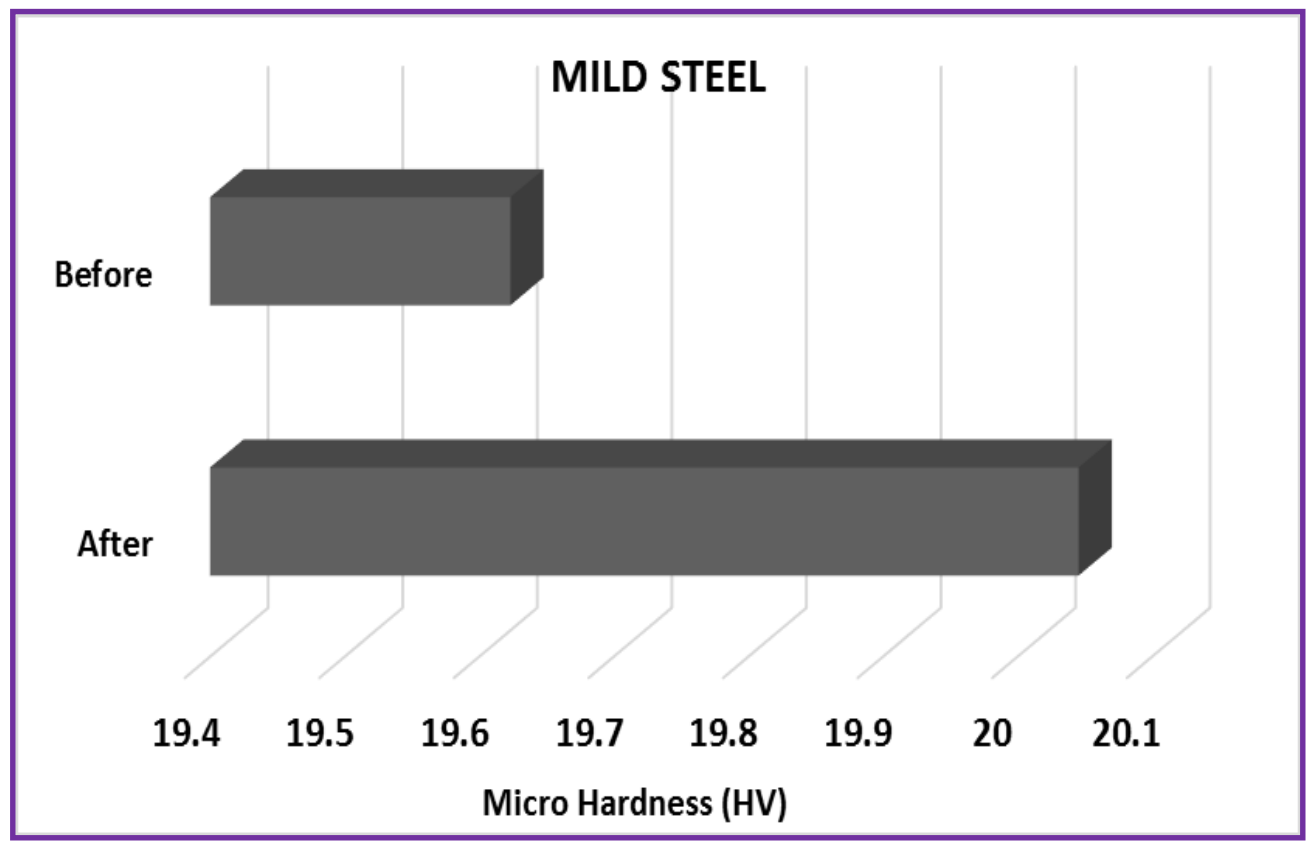

Fig 4:- Micro Hardness of Mild steel before and after plating. 


\section{Electrochemical Measurements:-}

Electrochemical measurements such as Tafel polarization and electrochemical impedance were carried out using electrochemical work station (CH604E0). The electrochemical cell consists of conventional three electrode Pyrex glass cell with platinum as counter electrode, saturated calomel electrode(SCE) as a reference electrode and mild steel specimen as working electrode and mild steel specimen as working electrode. The freshly deposited mild steel was studied in $3.65 \% \mathrm{NaCl}$ solution by galvanostatic polarization method. The steady state open circuit potential (OCP) was permitted to establish. Tafel plots were recorded soon after the impedance measurement by polarizing the specimen from $-250 \mathrm{mV}$ catholically to $+250 \mathrm{mV}$ anodically with respect to OCP at a scan rate $1 \mathrm{mVs}^{-1}$. The electrochemical properties of the $\mathrm{Zn}$ coatings were studied.

The corrosion performance of the $\mathrm{Zn}$ samples were measured using a linear Potentiodynamic scan and open circuit corrosion potential measurements technique in $3.65 \% \mathrm{NaCl}$. The deviation in open-circuit potential as a function of time for $\mathrm{Zn}$ coated samples and mild steel were tested in $3.65 \% \mathrm{NaCl}$ are presented in Fig 5 . The $\mathrm{Zn}$ coated $\mathrm{A}_{2}$ sample potential was observed to shift towards positive value compared to other $\mathrm{Zn}$ coated samples. The negative shift of the potential indicated the strong dissolution of the mild steel due to the absence of passivation. It is significant to indication that the positive shift of the potential indicates the formation of protective films and an increase in the passive film thicknesses. From all signs, sample $A_{2}$ as seen in Fig. 6 tends to form more stable passivity than the other coatings due to the large number of tiny particles deposited on the cathode at higher applied voltage.

Hence, these phenomena show that the Zinc content in the deposited metal strongly increases the corrosion resistance of the coatings. This implies that corrosion potential increased with $0.768 \mathrm{~V}$ and this increase may be traced to the presence of the deposited particles. Additionally, deposited samples displayed greatly reduced corrosion current in all instances as compared to the mild steel

Table 1:- Summary of the Potentiodynamic results

\begin{tabular}{|c|c|c|c|c|c|}
\hline Sample & $\mathrm{E}_{\text {corr }}(\mathrm{V})$ & $\beta_{\mathrm{a}}(1 / \mathrm{V})$ & $\beta_{\mathrm{c}}(1 / \mathrm{V})$ & $\mathrm{i}_{\text {Corr }}(\mathrm{A}) \mathrm{X} 10^{-4}$ & $\mathrm{CR}(\mathrm{mil} / \mathrm{yr}) \mathrm{X} 10^{-2}$ \\
\hline $\mathrm{A}$ & -0.6029 & 5.458 & 4.92 & 4.123 & 2.429 \\
\hline $\mathrm{A}_{1}$ & -0.6757 & 7.561 & 4.258 & 2.376 & 1.400 \\
\hline $\mathrm{A}_{2}$ & -0.6939 & 7.954 & 4.395 & 2.27 & 1.340 \\
\hline $\mathrm{A}_{3}$ & -0.7424 & 6.872 & 4.154 & 2.839 & 1.672 \\
\hline
\end{tabular}

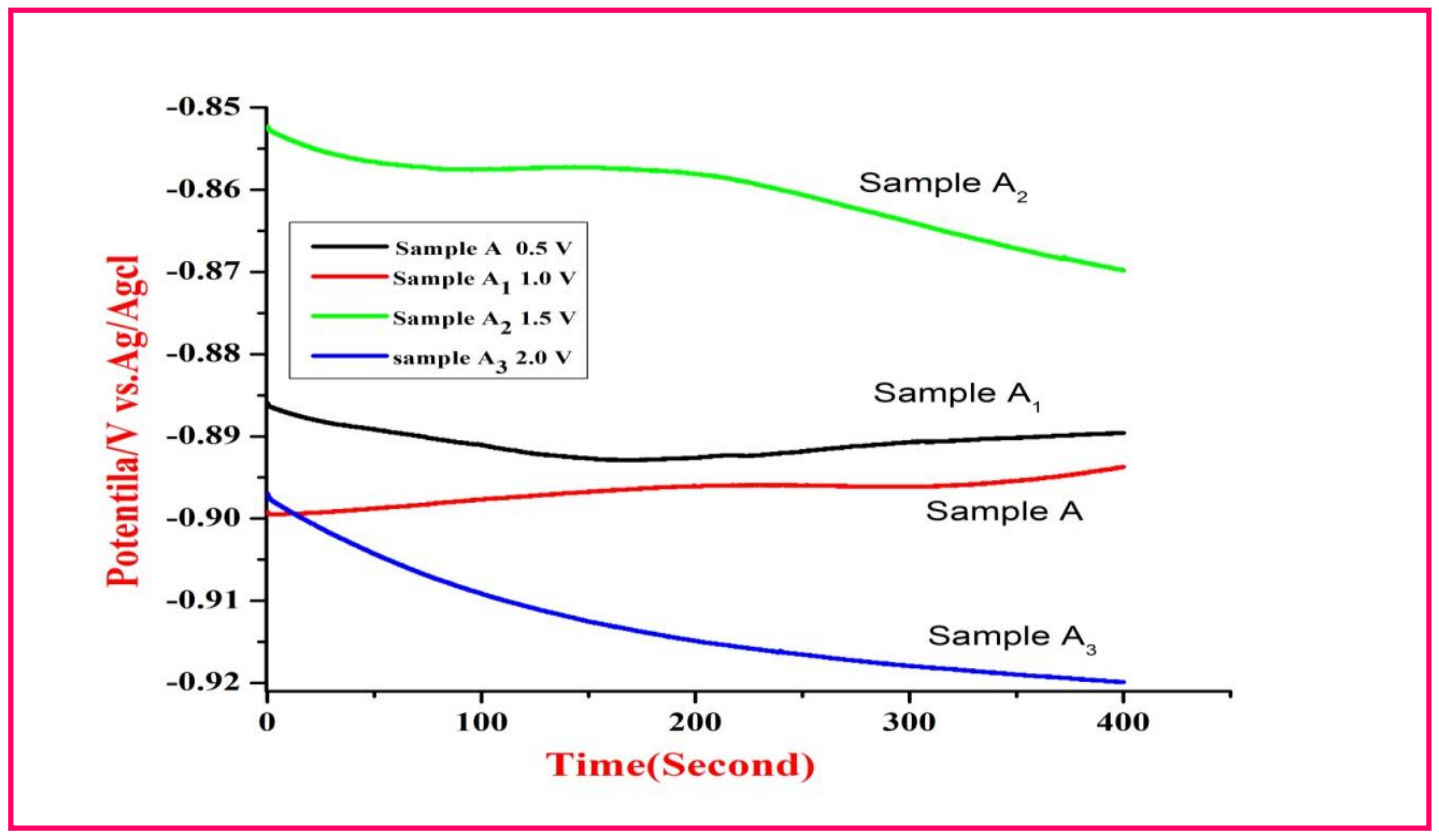

Fig 5:- Open circuit potential of $\mathrm{P}$ of $\mathrm{Zn}$ deposited mild steel 


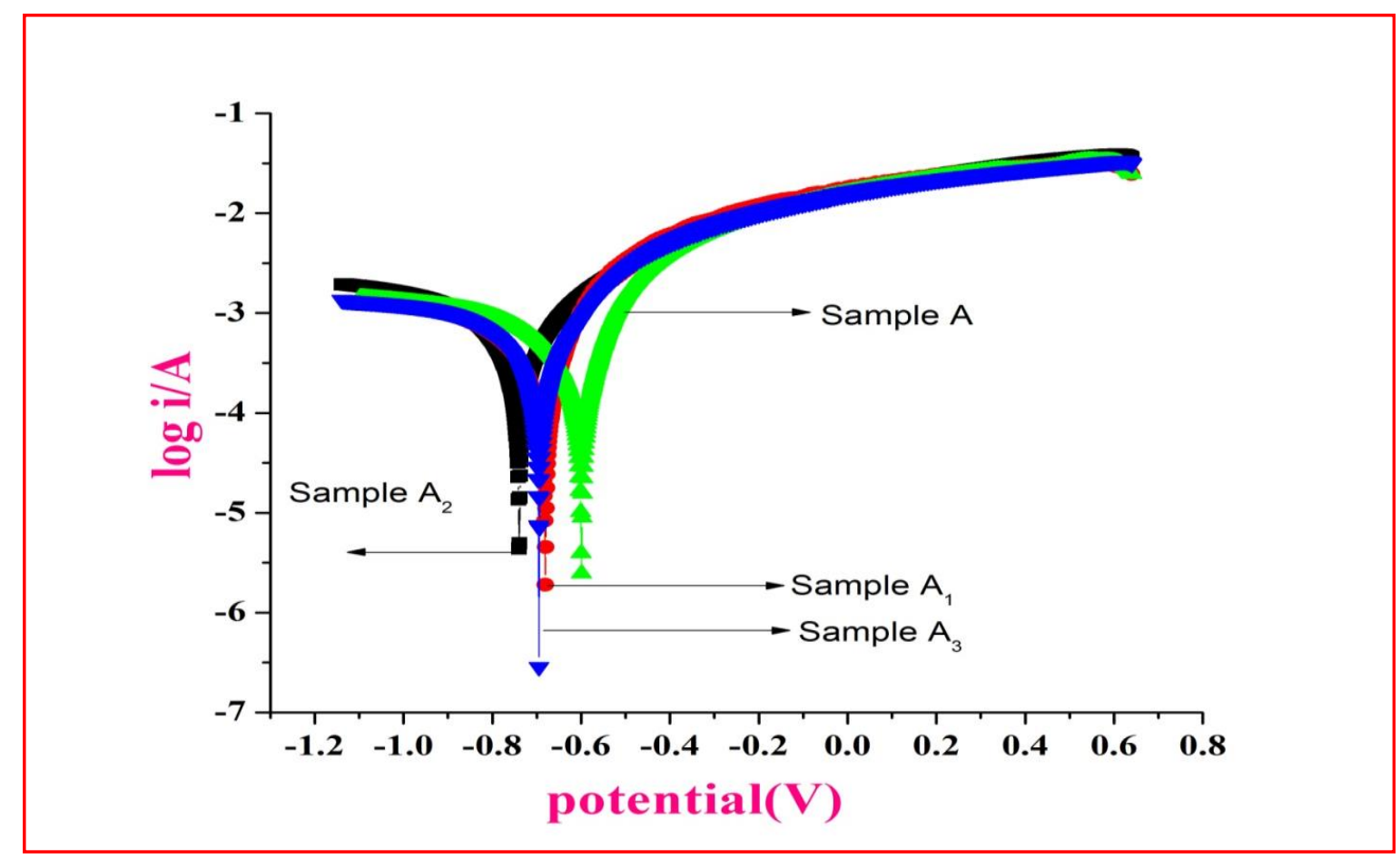

Fig 6:- Taffel plots of Zn deposited mild steel

\section{Conclusion:-}

Electro-deposition of Zinc from battery waste was successfully carried out on mild steel surface by electroplating method. Surface morphology, micro hardness, and Thickness and corrosion resistance of the coated samples were investigated with the following conclusions are obtained: Micro hardness value of the mild steel after electroplating increases of about $22 \%$ compared to that of before plating and coated sample clearly showed two times as much as the base material. Surface area and line roughness increases when coated with $\mathrm{Zn}$ compared to that of base material and showed highest $\mathrm{Zn}$ particles deposited on its surface. The electrochemical study revealed that corrosion resistance of mild steel was improved after zinc deposition. Zinc content in the deposited metal strongly increases the corrosion resistance of the coatings. .This implies that corrosion potential increased with $0.768 \mathrm{~V}$ and this increase may be traced to the presence of the deposited particles.

\section{Acknowledgment:-}

The one of the author (Mylarappa.M) thanks to the University grants commission (UGC), New Delhi and Rajiv Gandhi national fellowship, letter no F.14-34/2011(cpp-II), dated 11-01-2013 for the finance assistance to complete the research work. The authors also thank the management and Principal of SJRC for their encouragement in extending the facilities at SJRC and the Principal and management of East West Institute of Technology for providing electrochemical work station to complete the work.

\section{References:-}

1. P. S. D. Brito, S. Patrício, L. F. Rodrigues, D. M. F. Santos \& C. A. C. Sequeira, Electrodeposition of Zn-Mn alloys from recycling battery leach solutions in the presence of amines.

2. Paulo Sergio da Silva, Edinéia P. Sartori Schmitz, Almir Spinelli, Jarem Raul Garcia, Electrodeposition of Zn and $\mathrm{Zn}-\mathrm{Mn}$ alloy coatings from an electrolytic bath prepared by recovery of exhausted zinc-carbon batteries. 
3. Vaishaka Rao, KasturiV.Bangera, A.ChitharanjanHegde, Magnetically induced electrodeposition of Zn-Ni alloy coatings and their corrosion behaviors. Journal of Magnetism and Magnetic Materials 345 (2013)48-54.

4. N. Eliaz, K. Venkatakrishna, A. Chitharanjan Hegde, Electroplating and characterization of $\mathrm{Zn}-\mathrm{Ni}$, Zn-Co and Zn-Ni-Co alloys, Surface \& Coatings Technology 205 (2010) 1969-1978.

5. M.A. Deyab, Hydroxyethyl cellulose as efficient organic inhibitor of zinc-carbon battery corrosion in ammonium chloride solution: Electrochemical and surface morphology studies. Journal of Power Sources 280 (2015) 190e194.

6. P.M. Dasami , K. Parameswari, S. Chitra, Corrosion inhibition of mild steel in $1 \mathrm{MH}_{2} \mathrm{SO}_{4}$ by thiadiazole Schiff bases, Measurement 69 (2015) 195-201.

7. Heidi A. Conrad, Michael R. McGuire, Ting Zhou, M. Ibrahim Coskun, Teresa D. Golden Improved corrosion resistant properties of electrochemically deposited zinc-nickel alloys utilizing a borate electrolytic alkaline solution, Surface \& Coatings Technology 272 (2015) 50-57

8. Nitin P.Wasekar, A. Jyothirmayi, Neha Hebalkar, G. Sundararajan, Influence of pulsed current on the aqueous corrosion resistance of electrodeposited zinc

9. M. Tamilselvi, P. Kamaraj, M. Arthanareeswari, S. Devikala, Nano zinc phosphate coatings for enhanced corrosion resistance of mild steel 